\title{
Trends in US Kidney Transplantation During the COVID-19 Pandemic
}

Stephen J. Bordes ${ }^{1}$, Lisandro Montorfano ${ }^{2}$, Wesley West-Ortiz ${ }^{3}$, Roberto Valera ${ }^{2}$, Alejandro Cracco ${ }^{2}$, Mileydis Alonso ${ }^{2}$, Antonio D. Pinna ${ }^{2}$, Samer Ebaid ${ }^{2}$

1. Department of Anatomical Sciences, St. George's University School of Medicine, St. George's, GRD 2. Transplant, Cleveland Clinic Florida, Weston, USA 3. Transplant, American University of the Caribbean School of Medicine, Cupecoy, SXM

Corresponding author: Samer Ebaid, ebaids@ccf.org

\begin{abstract}
Solid organ transplants have been impacted significantly during the COVID-19 pandemic in the United States. Limited data exist regarding changes in living donor kidney transplants. The aim of this study was to describe national trends in kidney transplantation during COVID-19. This descriptive cross-sectional study used publicly available data from the United Network for Organ Sharing (UNOS) and the National Kidney Registry (NKR). Plots of national waitlist inactivations, waitlist additions, deceased donor transplants and living donor transplants were created. An Auto Regressive Integrated Moving Average (ARIMA) model with interrupted time series analysis adjusting for first-order autocorrelation was used to evaluate for significant changes in outcome trends every four-week period during the COVID-19 era between March 15 and August 1, 2020. A statistical significance of 0.05 ( $\mathbb{(})$ was established for analysis. Changes in kidney transplant volumes during the COVID-19 outbreak were registered. Density mapping and linear regression with interrupted time series analysis were used to characterize changes over time nationwide. Kidney transplants were affected significantly in recent months due to COVID-19. Deceased donor and living donor kidney transplant trends are described in this paper in addition to operative recommendations.
\end{abstract}

Review began 11/19/2020 Review ended 12/07/2020 Published 12/14/2020

\section{(c) Copyright 2020}

Bordes et al. This is an open access article distributed under the terms of the Creative Commons Attribution License CC-BY 4.0., which permits unrestricted use, distribution, and reproduction in any medium, provided the original author and source are credited.
Categories: Infectious Disease, Transplantation

Keywords: covid-19, sars-cov-2, kidney transplantation, kidney transplant, living donor program, living donor kidney transplant, deceased donor kidney transplant, pandemic

\section{Introduction}

The novel 2019 coronavirus (SARS-CoV-2 or COVID-19) is considered the pandemic of the current century [1]. The virus rapidly spread worldwide and has been recognized as a global public health crisis due to a shortage of resources to care for the growing number of patients with acute respiratory distress syndrome (ARDS) and other complications resulting from SARS-CoV-2 [2,3]. By July 30, 2020, 136,577 deaths related to COVID-19 had been reported in the United States, posing another obstacle to an already challenging delivery of care with renal transplantation [4]. To potentially minimize virus exposure to both living organ donors and transplant recipients, programs temporarily postponed some or all living donor kidney transplants.

There are several ways to address end-stage renal disease (ESRD) depending on patient preference and severity of disease. Patients can receive lifelong hemodialysis or peritoneal dialysis, or they can be listed for kidney transplantation. Living donor nephrectomy was introduced to address the shortage of deceased donor kidneys [5]. The first deceased donor kidney transplant was accomplished in 1945, followed by the first living donor kidney transplant in 1953 and the first living-related renal transplant in 1954 [6,7]. The availability of organs remains the most significant factor limiting kidney transplants in ESRD patients.

COVID-19 has impacted transplantation centers globally. Many hospitals suspended transplant procedures to varying degrees due to concerns of infection transmission, resource allocation, and immunosuppression complications [8]. While much remains to be discovered regarding COVID-19, its early impact on transplantation is both profound and underrecognized. According to data released by the United Network for Organ Sharing (UNOS), 2019 marked the 7th record-setting year for transplants in the United States as can be recognized from an $8.7 \%$ increase in overall transplants, a $10.7 \%$ increase in deceased donor transplants, and a 5.8\% increase in living donor transplants from 2018 [9]. While 2020 could once again mark another record-setting transplant year, temporary suspension of the living donor program in March proved to be a significant setback as living donations fell by nearly $50 \%$ overall for the 2020 year-to-date [9].

Over the last few months, a robust number of articles have been published describing the devastating impact of this virus in the world of surgery [8,10-14]. However, to the best of our knowledge, this is the first report describing the impact of COVID-19 on living donor kidney transplants and necessitates particular attention. 
pandemic, we bring to attention our concern regarding the shutdown of living donor kidney transplant programs. 23,401 kidney transplants were performed in 2019. Nevertheless, the waiting list remains substantially larger than the supply of donor kidneys [15]. Unfortunately, those who remain on the waiting list require renal replacement therapy for the treatment of ESRD. Even during non-pandemic times, patients on hemodialysis are 10 to 30 times more likely to expire compared to the general population [16,17]. With this in mind, our article aims to assess the changes in living donor kidney transplant volumes from the preCOVID-19 (January 1, 2019 - March 14, 2020) to the present COVID-19 era (March 15 - August 1, 2020) and provide recommendations regarding safe living donor kidney transplantation during the COVID-19 pandemic while simultaneously avoiding future interruption of living donor programs throughout the nation.

\section{Materials And Methods}

Renal transplant data was publicly obtained from the United Network for Organ Sharing (UNOS) and the National Kidney Registry (NKR). Year-to-date living and deceased kidney donor transplants were charted and compared to trends from 2019. Data was broken down in terms of total 2019 renal transplants, total 2020 year-to-date transplants per week, 2020 living donor year-to-date transplants per week, and total 2020 deceased donor year-to-date transplants per week. Year-to-date waitlist additions and inactivations were also considered. Given that data were publicly available with deidentified information, institutional review board (IRB) approval and informed consent were not required as per institutional policy.

On March 11, 2020 the Novel Coronavirus Disease (COVID-19), was declared a pandemic by the World Health Organization (WHO). On March 13, 2020, a national emergency was declared in the United States concerning the COVID-19 Outbreak. As of March 15, 2020, UNet (the electronic system managed by UNOS that allows transplant professionals to submit, store, and manage transplant-associated data) users could denote if waitlist inactivations were due to COVID-19 precautions. Therefore, for this analysis, the period from January 1, 2019 to March 14, 2020 was designated the pre-COVID-19 era while the period from March 15 to August 1, 2020, was designated as the present COVID-19 era.

International Business Machines (IBM) Statistical Product and Service Solutions (SPSS) software (Armonk, NY) was used for statistical analysis. Plots of national waitlist inactivations, waitlist additions, deceased donor transplants and living donor transplants were created using spreadsheets. An Auto Regressive Integrated Moving Average (ARIMA) model with interrupted time series analysis adjusting for first-order autocorrelation was used to evaluate for significant changes in outcome trends every 4-week period during the COVID-19 era. A statistical significance of $0.05(\mathbb{X})$ was established for analysis.

\section{Results}

\section{Changes in $\mathbf{2 0 2 0}$ monthly data}

There were a total of 5,071 transplants in the 2020 pre-COVID-19 era compared to 7,799 during the pandemic, which represented an increase of $53.8 \%$, a lower increase compared to the $97.6 \%$ increase found in the 2019 data for the same periods. For the 2020 year to year data, we found a trend of 958.54 new transplants per month $(\mathrm{p}<0.001)$, higher than the 901.01 transplants per month trend of the last year $(\mathrm{p}$ 0.001).

There were a total of 1,329 living donor transplants in 2020 pre-COVID-19 compared to 1508 during the pandemic, which represented an increase of $13.4 \%$, compared to the $43 \%$ increase found in the 2019 data for the same periods. For the 2020 data, we found a trend of 195.13 new transplants per month ( $\mathrm{p}^{<} 0.001$ ), lower than the 286.77 transplants per month trend of the last year $\left(\mathrm{p}^{<} 0.001\right)$ (Tables 1,2 ; Figures 1,2$)$.

\begin{tabular}{|c|c|c|c|c|c|c|}
\hline & January 5 - March 15 & March $15-$ August 1 & $\Delta \%$ & Estimate of effect & Standard Error & p-value \\
\hline Total & 4527 & 8945 & +97.6 & +958.54 & 14.83 & 0.001 \\
\hline Deceased & 3149 & 6228 & +97.8 & +670.63 & 4.94 & 0.001 \\
\hline Living & 1378 & 2717 & +97.2 & +286.77 & 9.73 & 0.001 \\
\hline
\end{tabular}

TABLE 1: Trends in year-to-date total, deceased donor, and living donor transplants in 2019. 


\section{Cureus}

\begin{tabular}{|c|c|c|c|c|c|c|}
\hline & Pre COVID-19 & COVID-19 & $\Delta \%$ & Estimate of effect & Standard Error & p-value \\
\hline Total & 5071 & 7799 & +53.8 & +901.01 & 34.45 & 0.001 \\
\hline Deceased & 3742 & 6291 & +68.1 & +704.29 & 20.38 & 0.001 \\
\hline Living & 1329 & 1508 & +13.4 & +195.13 & 16.49 & 0.001 \\
\hline
\end{tabular}

TABLE 2: Trends in year-to-date total, deceased donor, and living donor transplants in 2020.

$\Delta$ (delta), difference in value.

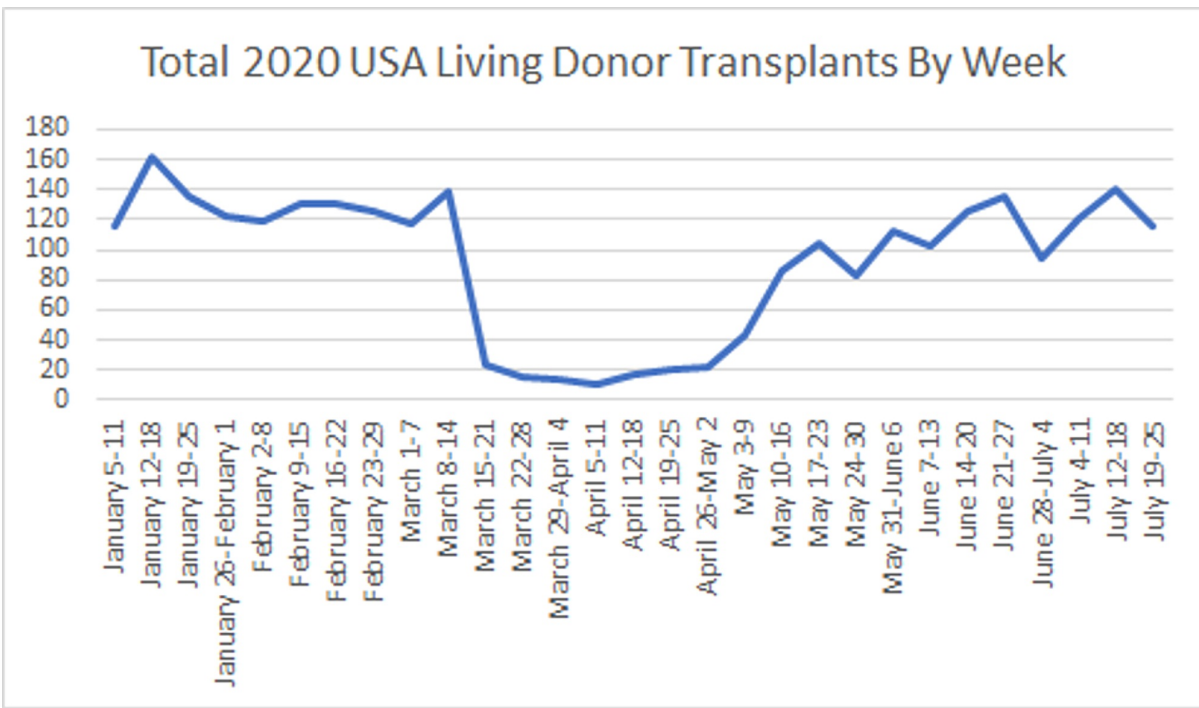

FIGURE 1: Total 2020 living donor kidney transplants in the United States by week.

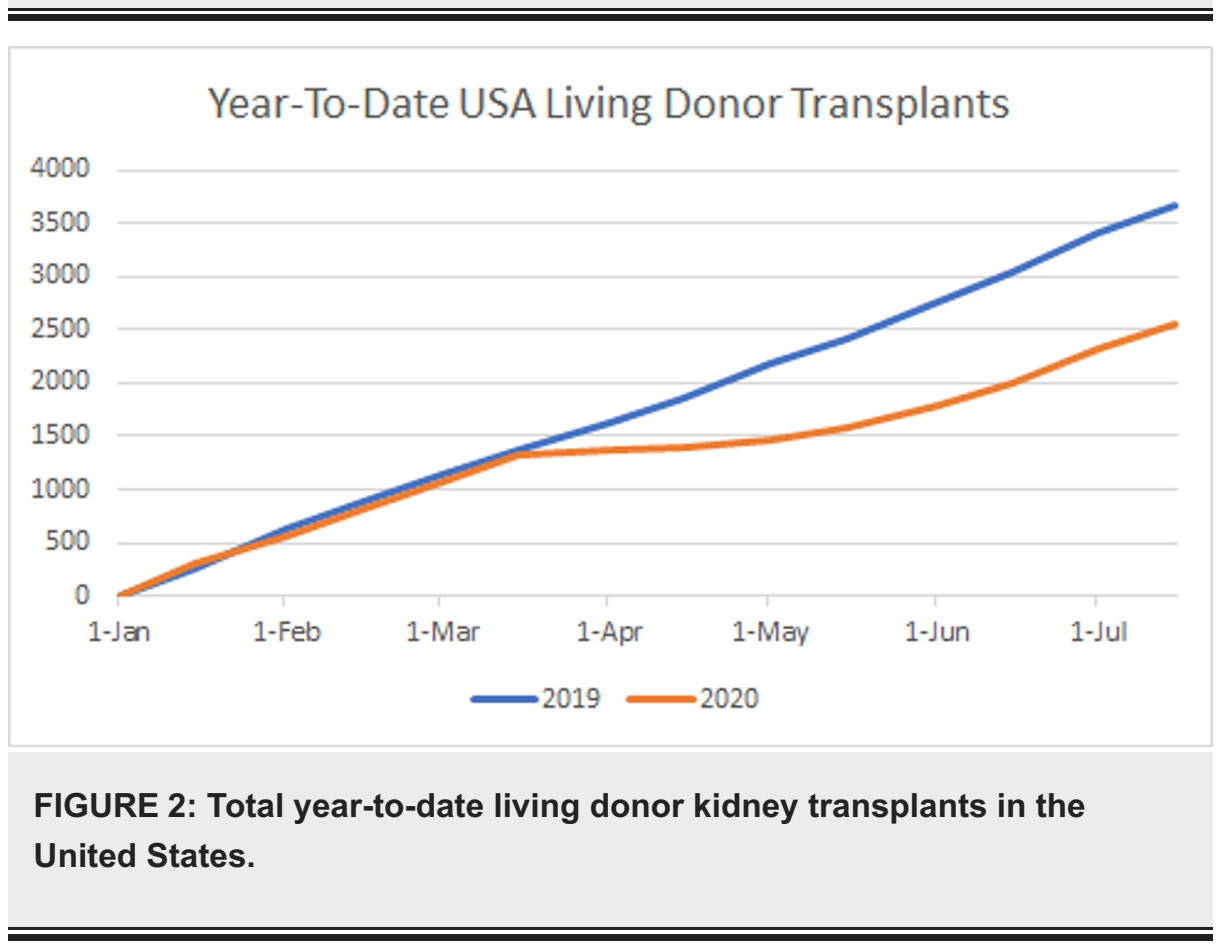

Lastly, the total number of deceased donor transplants pre-COVID-19 era was 3742 compared to 6,291 during the pandemic. This represented an increase of $68.1 \%$, a lower increase compared to the $97.8 \%$ increase 


\section{Cureus}

found in the 2019 data for the same periods. However, we found a trend of 704.29 new transplants per month $(\mathrm{p}<0.001)$, higher than the 670.63 transplants per month trend of the last year $(\mathrm{p}<0.001)$ (Figures 3,4$)$.

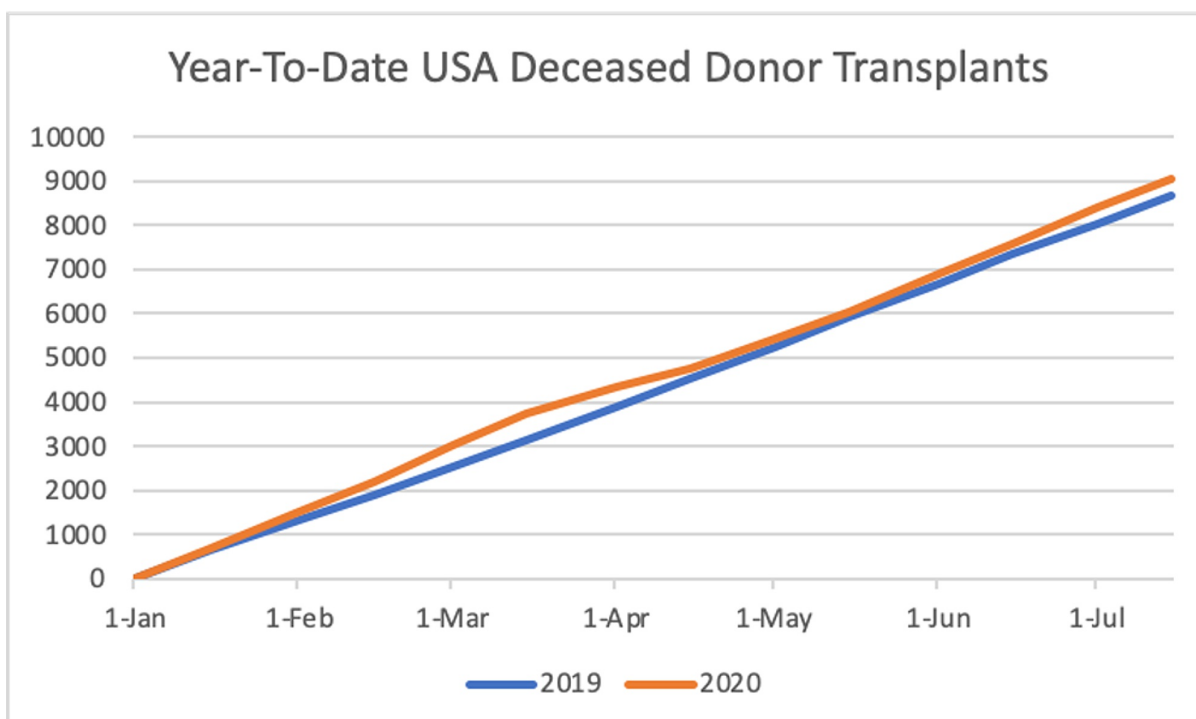

FIGURE 3: Total year-to-date deceased donor kidney transplants in the United States.

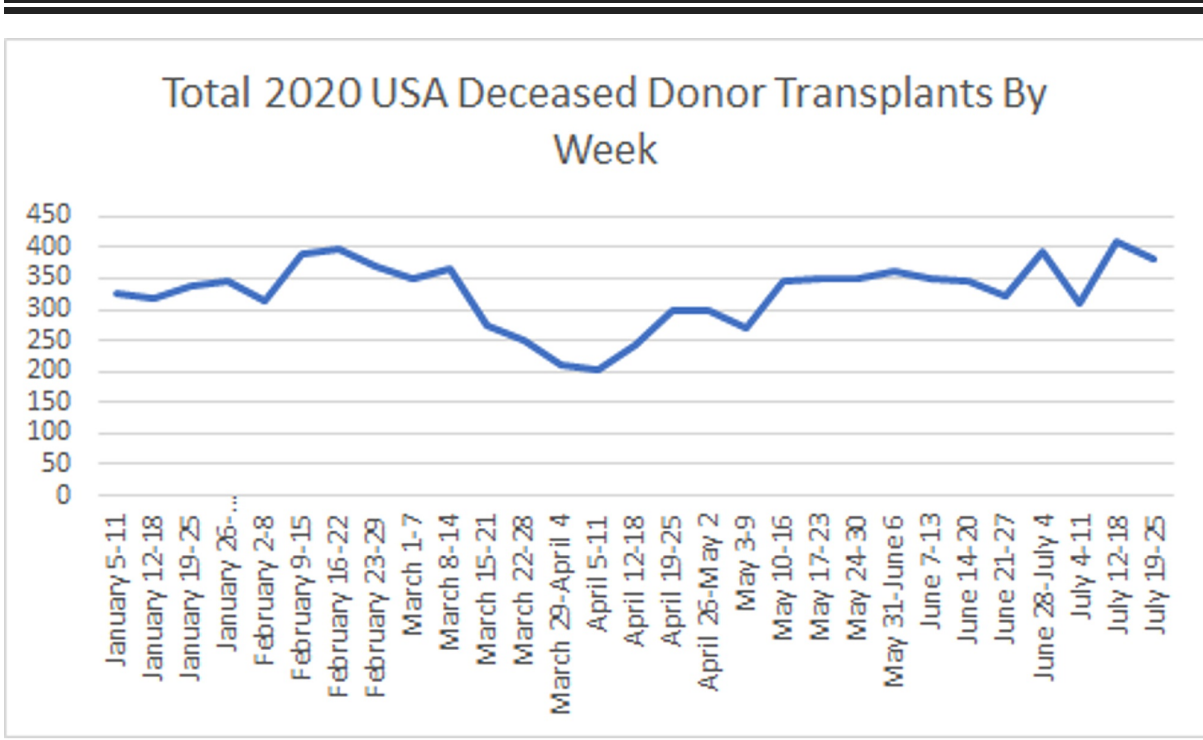

FIGURE 4: Year-to-date deceased donor kidney transplants in the United States by week.

\section{Changes in 2020 weekly data}

We found significant changes in the deceased donor trends for the first three 4-week periods of the COVID19 era. The mean difference in deceased donor transplants per week (2019 vs. 2020) for the periods March 15 - April 11, April 12 - May 10, and May 11 - June 7 were -148.82 (CI = -206.29; -91.34, $\left.\mathrm{p}^{<} 0.001\right),-137.34$ (CI = $\left.-217.58 ;-57.10, \mathrm{p}^{<} 0.001\right)$ and $-125.87(\mathrm{CI}=-234.50 ;-17.24, \mathrm{p}=0.022)$ (Table 3$)$. 


\section{Cureus}

\begin{tabular}{|c|c|c|c|c|}
\hline Period & Estimate of effect & Standard Error & Confidence Interval & p-value \\
\hline Pre-COVID-19 era & +5.91 & 3.70 & $-1.87 ; 13.70$ & 0.122 \\
\hline March 15 - April 11 & -148.82 & 27.24 & $-206.29 ;-91.34$ & 0.001 \\
\hline April 12 - May 10 & -137.34 & 38.03 & $-217.58 ;-57.10$ & 0.001 \\
\hline May 11 - June 7 & -125.87 & 51.49 & $-234.50 ;-17.24$ & 0.022 \\
\hline June 8 - July 4 & -114.40 & 66.00 & -253.65; 24.85 & 0.096 \\
\hline July 4 - July $25^{*}$ & -102.94 & 81.01 & $-273.84 ; 67.97$ & 0.216 \\
\hline
\end{tabular}

TABLE 3: Changes in trend of deceased donor transplants per four-week period during the COVID-19 era.

Regarding living donor transplants, the first two 4-week periods of the COVID-19 era showed a significant decrease. Between March 15 and April 11, a mean decrease of 120.37 cases per week was found (CI $=-152.58$; -88.16, $\mathrm{p}<0.001)$. The April 12 - May 10 period showed a decrease of 87.99 cases per week ( $\mathrm{CI}=-133.27$; 42.71, $\left.\mathrm{p}^{<} 0.001\right)$ (Table 4).

\begin{tabular}{|c|c|c|c|c|}
\hline Period & Estimate of effect & Standard Error & Confidence Interval & p-value \\
\hline Pre-COVID-19 era & -0.71 & 2.10 & $-5.10 ; 3.68$ & 0.737 \\
\hline March 15 - April 11 & -120.37 & 15.33 & $-152.58 ;-88.16$ & 0.001 \\
\hline April 12 - May 10 & -87.99 & 21.55 & $-133.27 ;-42.71$ & 0.001 \\
\hline May 11 - June 7 & -55.61 & 29.18 & $-116.90 ; 5.69$ & 0.068 \\
\hline June 8 - July 4 & -23.26 & 37.35 & $-101.69 ; 55.24$ & 0.539 \\
\hline July 4 - August 1 & +9.16 & 45.78 & $-87.02 ; 105.33$ & 0.843 \\
\hline
\end{tabular}

TABLE 4: Changes in trend of living donor transplants per four-week period during the COVID-19 era.

Finally, we analyzed the changes in the trends of waitlist inactivations up to August 1. A total of 19,431 inactivations were reported during the COVID-19 era, of which 7,846 (40.38\%) were due to SARS-CoV-2 infection. We found that the number of all-cause inactivation per week increased for the March 15 - April 11 and April 12 - May 10 periods, with $1596.07\left(\mathrm{CI}=901.23 ; 2,290.94, \mathrm{p}^{<} 0.001\right)$ and 1,333.12 (CI = 356.24; $2,310.01, p=0.008$ ) inactivations per week respectively. The trend of COVID-19-related inactivations change significantly only during the March 15 - April 11 period ( +1080.42 inactivations per week, $\mathrm{CI}=493.92$; 1,666.93, $\mathrm{p}=0.001)($ Tables 5, 6; Figures 5, 6). 


\section{Cureus}

\begin{tabular}{|c|c|c|c|c|}
\hline Period & Estimate of effect & Standard Error & Confidence Interval & p-value \\
\hline March 15 - April 11 & +1596.07 & 330.74 & $901.23 ; 2290.94$ & 0.001 \\
\hline April 12 - May 10 & +1333.12 & 464.98 & $356.24 ; 2310.01$ & 0.008 \\
\hline May 11 - June 7 & +1070.16 & 629.39 & $-252.13 ; 2392.45$ & 0.101 \\
\hline June 8 - July 4 & +807.20 & 805.70 & -885.52; 2499.92 & 0.326 \\
\hline July 4 - August 1 & +544.24 & 987.57 & $-1530.57 ; 2619.04$ & 0.586 \\
\hline
\end{tabular}

TABLE 5: Changes in trend of all-cause inactivations per four-week period during the COVID-19 era.

\begin{tabular}{|c|c|c|c|c|}
\hline Period & Estimate of effect & Standard Error & Confidence Interval & p-value \\
\hline March 15 - April 11 & +1080.42 & 279.17 & 493.92; 1666.93 & 0.001 \\
\hline April 12 - May 10 & +808.75 & 392.74 & $-16.37 ; 1633.90$ & 0.050 \\
\hline May 11 - June 7 & +537.05 & 530.47 & $-577.42 ; 1651.51$ & 0.321 \\
\hline June 8 - July 4 & +266.01 & 677.75 & $-1157.88 ; 1689.90$ & 0.698 \\
\hline July 4 - August 1 & -5.577 & 829.536 & $-1748.37 ; 1737.21$ & 0.995 \\
\hline
\end{tabular}

TABLE 6: Changes in trend of COVID-19-related inactivations per four-week period during the COVID-19 era. 


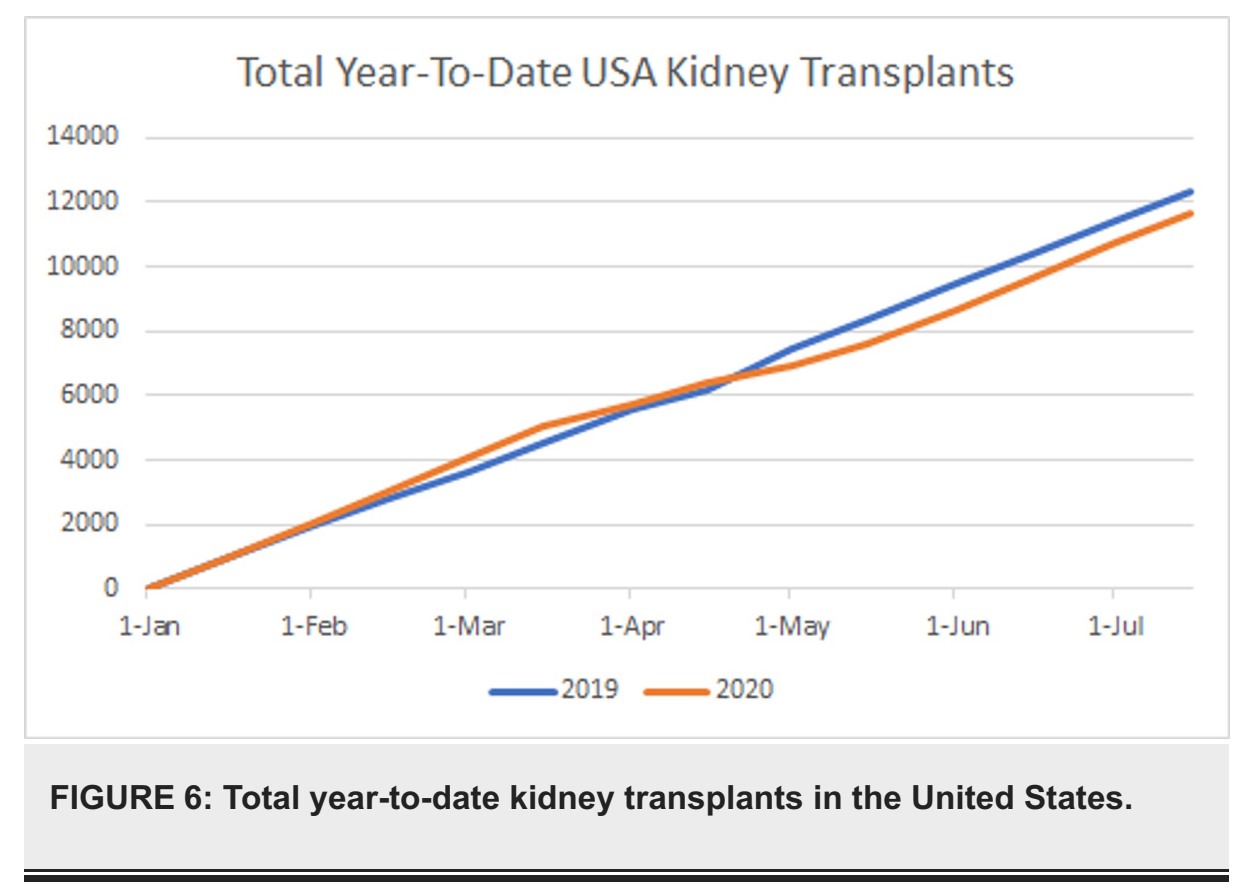

Discussion

Herein, we describe national trends in kidney transplants during the COVID-19 pandemic. COVID-19 has been negatively impacting solid organ transplantation services worldwide. As the pandemic continues to progress, transplant centers face numerous challenges that have led to a steep decline in all solid organ transplants. As of August 1, 2020, the United States has registered 22,208 total solid organ transplants. From January 2019 to December 2019, the United States recorded 39,719 total transplants, an 8.7\% increase from 2018 which recorded 36,269 total solid organ transplants [18]. Currently, deceased donor kidney year-to-date transplants are outpacing those from the same period in 2019 (9,982 between January 1, 2020 and August 1, 2020 vs. 9,329 between January 1, 2019 and August 1, 2019; Figure 3). However, deceased donor kidney transplantations decreased by 35\% in April due to COVID-19 procurement measures [19]. By June 2, 2020, deceased donor kidney transplants returned to $95 \%$ of pre-COVID era numbers [20]. The kidney living donor program came to a near halt between March 15 and May 9, 2020. The National Kidney Registry reported an 89\% drop in living donor transplants in April, which was due to concerns surrounding laparoscopy and donor safety during the COVID-19 pandemic [19]. Living donor transplants returned to $71 \%$ of pre-COVID-19 rates as of June 2, 2020 and kidney paired donations reached levels of 63\%. A surge in kidney transplants is predicted in the Fall of 2020 due to a delay in kidney paired donations [20].

A study on COVID-19 transmission dynamics in Wuhan, China reports that human-to-human transmission among close contacts is a primary method of virus spread [21]. Due to potential droplet transmission by asymptomatic patients, COVID-19 can be spread rapidly within the healthcare community. Various COVID19 outbreaks have been reported in multiple hospital settings [22-27]. A report from Wuhan showed $12 \%$ of 138 inpatient COVID-19 cases were acquired during hospital admissions [28]. Other hospitals reported similar numbers [22,28]. Living donor kidney transplant procedures may allow 4 to 5 hours of continuous COVID-19 aerosol exposure. We believe the potential risk of transmission due to aerosolization of the virus while performing laparoscopic surgery and the risk of viral transmission from healthcare workers and COVID-19 positive patients to living donor transplant donors and recipients were the main concerns that drove transplant centers to perform fewer living donor kidney transplants during the COVID-19 outbreak.

Based on our review of the available data and new transplant guidelines, we strongly recommend that every hospital in which COVID-19 patients are treated and living donor transplants are performed should ensure that patients have at least two negative COVID-19 tests prior to surgery (14 days and 24-72 hours preoperatively) in addition to a period of self-quarantine leading up to organ donation [29]. At our institution, we routinely perform three COVID-19 respiratory nucleic amplification tests (NATs), including a third rapid COVID-19 test on the morning of surgery.

Proper donning and doffing in the anteroom using adequate personal protective equipment should be employed by physicians that perform surgeries on all patients, regardless of COVID-19 status. This includes N95 mask, cap, boot covers, sterile gowns, gloves, face and eye protection covers. In order to minimize the risk of viral transmission between COVID-19 positive patients, transplant patients, and hospital staff, a minimum number of staff should be present for the duration of COVID-19 related procedures. This includes one lead surgeon and one to two operating assistants. We recommend one circulating nurse, one anesthetist, and one scrub technician. 
Another measure that can be undertaken in order to minimize the risk of viral transmission studies is performing laparoscopic surgery in negative-pressure operating rooms with an in-room high-efficiency particulate air (HEPA) filter to ensure maximum air purification as recommended in previous studies [11]. Generally, viruses travel inside air droplets that comprise the aerosol. Nearly all aerosols are removed by modern ventilation HEPA systems that filter operating rooms [11]. Prior studies at our institution also highlight precautions for toxic aerosolized pneumoperitoneum during laparoscopy. These additional recommendations include minimal abdominal carbon dioxide (CO2) insufflation, minimal use of trocars (2 recommended), desufflation of toxic aerosols, and plastic draping of the patient with underlying HEPA filtration [11].

The average waitlist time for a kidney transplant is three to five years and depends on a variety of factors. Patients with a high panel reactive antibody (PRA) are even less likely to find an organ match due to higher immunoreactivity and thus higher chances of organ rejection. Some transplant centers across the country have reported cases of patients with high PRA that have lost their opportunity to receive a kidney transplant due to the fact that they tested positive for COVID-19 the day of the surgery. Unfortunately, those who remain on the waiting list require renal replacement therapy for treatment of ESRD. For the majority of patients with end-stage renal disease, hemodialysis is the mainstay of treatment. Three times per week, hemodialysis patients remain indoors for 4 hours in frequent contact with other patients and healthcare staff increasing their risk of acquiring COVID-19. Morbidity and mortality rates in dialysis patients are significantly higher compared to the non-dialysis population. In April 2020, the kidney transplant waitlist patient mortality rate increased by $43.0 \%$ based on available UNOS data. A $170 \%$, 89\%, and 54\% solid organ transplant waitlist all-cause mortality increase was reported in UNOS regions 9, 1, and 2, respectively [30]. Northeast Region 2, which includes New York, noted a two-fold increase in kidney waitlist mortality [30]. For these reasons, we recommend no future suspension of living donor transplants due to reasons attributed to COVID-19 if the above safety procedures are employed. Risks to both patients and staff remain acceptable when adequate precautions are undertaken.

\section{Conclusions}

COVID-19 has had direct and indirect associations with kidney transplantation in the United States. This article described national trends in kidney transplants during the COVID-19 pandemic. While the overall kidney transplant rate has remained stable year-to-date, living donor transplants decreased drastically at the onset of the pandemic. Although there is no single, universally agreed upon set of answers, we have presented what we believe is a balanced, compelling description of safe approaches to operate on COVID-19 patients and prevent living donor kidney transplantation contagions during the current COVID-19 outbreak. Transplant surgeons should be prepared for COVID-19 related kidney transplant inactivations and waitlist mortalities related to ESRD. In summary, we recommend no future suspension of the living donor program and no future transplant interruptions for high PRA recipients as chances of secondary organ match are low.

\section{Additional Information \\ Disclosures}

Human subjects: All authors have confirmed that this study did not involve human participants or tissue. Animal subjects: All authors have confirmed that this study did not involve animal subjects or tissue. Conflicts of interest: In compliance with the ICMJE uniform disclosure form, all authors declare the following: Payment/services info: All authors have declared that no financial support was received from any organization for the submitted work. Financial relationships: All authors have declared that they have no financial relationships at present or within the previous three years with any organizations that might have an interest in the submitted work. Other relationships: All authors have declared that there are no other relationships or activities that could appear to have influenced the submitted work.

\section{References}

1. Chakraborty I, Maity P: COVID-19 outbreak: migration, effects on society, global environment and prevention. Sci Total Environ. 2020, 728:138882. 10.1016/j.scitotenv.2020.138882

2. Prescott K, Baxter E, Lynch C, et al.: COVID- 19: how prepared are front line healthcare workers in England? J Hosp Infect. 2020, 105:142-145. 10.1016/j.jhin.2020.04.031

3. Montorfano L, Miret R, Rahman AU, et al.: Colorectal surgery obesity-related morbidity during COVID-19. Surg Obes Relat Dis. 2020, 16:1372-1375. 10.1016/j.soard.2020.06.011

4. Center for Disease Control and Prevention. Coronavirus Disease 2019 (COVID-19). Cases, Data and Surveillance. https://www.cdc.gov/coronavirus/2019-ncov/cases-updates/cases-in-us.html..

5. Alston C, Spaliviero M, Gill IS: Laparoscopic donor nephrectomy. Urology. 2005, 65:833-839. 10.1016/j.urology.2004.10.027

6. Smith SL: Tissue and Organ Transplantation: Implications for Professional Nursing Practice. St. Louis: Mosby; 1990.

7. Merril JP, Murray JE, Arrison JH: Successful homotransplantation of human kidney between identical twins . JAMA. 1956, 160:277-282. 10.1001/jama.1956.02960390027008

8. Guha C, Tong A, Baumgart A, et al.: Suspension and resumption of kidney transplant programs during the COVID-19 pandemic: perspectives from patients, caregivers and potential living donors-a qualitative study. Transplant International. 2020, 33:1481-1490. 10.1111/tri.13697 
9. United Network for Organ Sharing. Organ donation again sets record in 2019 . https://unos.org/news/organdonation-sets-record-in-2019..

10. Diaz A, Sarac BA, Schoenbrunner AR, et al.: Elective surgery in the time of COVID-19. Am J Surg. 2020, 219:900-902. 10.1016/j.amjsurg.2020.04.014

11. Wexner SD, Cortés-Guiral D, Gilshtein H, et al.: COVID- 19: impact on colorectal surgery. Colorectal Dis. 2020, 22:635-640. 10.1111/codi.15112

12. Steward JE, Kitley WR, Schmidt CM, et al.: Urologic surgery and COVID- 19: how the pandemic is changing the way we operate. J Endourol. 2020, 34:541-549. 10.1089/end.2020.0342

13. Hussain A, Mahawar K, El-Hasani S: The impact of COVID-19 pandemic on obesity and bariatric surgery . Obes Surg. 2020, 30:3222-3223. 10.1007/s11695-020-04637-7

14. Giunta RE, Frank K, Costa H, et al.: The COVID-19 pandemic and its impact on plastic surgery in Europe - an ESPRAS survey. Handchir Mikrochir Plast Chir. 2020, 52:221-232. 10.1055/a-1169-4443

15. United States Government Information on Organ Donation and Transplantation. Organ Donation Statistics . https://www.organdonor.gov/statistics-stories/statistics.html.

16. Kobayashi S, Keiko S, Mio U, et al.: A simple protein-energy wasting score for survival prediction of maintenance hemodialysis patients. Renal Replacement Therapy. 2015, 1:1. 10.1186/s41100-015-0012-0

17. Chantrel F, de Cornelissen F, Deloumeaux J, et al.: registre REIN Survival and mortality in ESRD patients . Néphrolo Thér. 2013, 9:S127-S137. 10.1016/s1769-7255(13)70042-7

18. United Network for Organ Sharing. Transplant Trends . (2020). Accessed: August 7, 2020: https://unos.org/data/transplant-trends..

19. COVID Updates: Training Call for New Donor Testing Policy. April Communication . (2020). Accessed: April 24, 2020: https://www.kidneyregistry.org/.

20. National Kidney Registry: NKR Logistics. COVID Assessment. Accessed: June 2, 2020: https://www.kidneyregistry.org/pages/p589/NKR_COVID19_Assessment.php.

21. Li Q, Guan X, Wu P, et al.: Early transmission dynamics in Wuhan, China of novel coronavirus-infected pneumonia. N Engl J Med. 2020, 382:1199-1207. 10.1056/NEJMoa2001316

22. Rickman H, Rampling T, Shaw K, et al.: Nosocomial transmission of COVID- 19: a retrospective study of 66 hospital-acquired cases in a London teaching hospital. Clin Infect Dis. 2020, ciaa816. 10.1093/cid/ciaa816

23. Arons MM, Hatfield KM, Reddy SC, et al.: Presymptomatic SARS-CoV-2 infections and transmission in a skilled nursing facility. N Engl J Med. 2020, 382:2081-2090. 10.1056/NEJMoa2008457

24. Zhou F, Yu T, Du R, et al.: Clinical course and risk factors for mortality of adult inpatients with COVID-19 in Wuhan, China: a retrospective cohort study. Lancet. 2020, 395:1054-1062. 10.1016/S01406736(20)30566-3

25. Wang X, Zhou Q, He Y, et al.: Nosocomial outbreak of COVID-19 pneumonia in Wuhan, China . Eur Respir J. 2020, 55:2000544. 10.1183/13993003.00544-2020

26. Van Praet JT, Claeys B, Coene AS, et al.: Prevention of nosocomial COVID- 19: another challenge of the pandemic. Infect Control Hosp Epidemiol. 2020, 41:1355-1356. 10.1017/ice.2020.166

27. Meredith LW, Hamilton WL, Warne B, et al.: Rapid implementation of SARS-CoV-2 sequencing to investigate cases of health-care associated COVID-19: a prospective genomic surveillance study. Lancet. 2020, 20:1263-1272. 10.1016/S1473-3099(20)30562-4

28. Wang D, Hu B, Hu C, et al.: Clinical characteristics of 138 hospitalized patients with 2019 novel coronavirus-infected pneumonia in Wuhan, China. JAMA. 2020, 323:1061-1069. 10.1001/jama.2020.1585

29. American Society of Transplantation. 2019-nCov: Recommendations and Guidance for Organ Donor Testing. (2020). Accessed: August 16, 2020:

https://www.myast.org/sites/default/files/sites/default/Donor\%20Testing\%20Document_Updated_2020_0708.pdf.

30. Cholankeril G, Podboy A, Alshuwaykh O, et al.: Early impact of COVID-19 on solid organ transplantation in the United States. Transplantation. 2020, 104:2221-2224. 10.1097/TP.0000000000003391 